\title{
A Literatura dos Povos Indígenas e a Formação do Leitor Multicultural
}

Janice Cristine Thiél'

'Pontifícia Universidade Católica do Paraná (PUC-PR), Curitiba/PR - Brasil

RESUMO - A Literatura dos Povos Indígenas e a Formação do Leitor Multicultural. Este artigo apresenta uma discussão sobre a presença e as características estético-literárias das textualidades indígenas. Tem como objetivo desenvolver uma reflexão sobre como o contato com esta literatura pelo público formado por crianças e jovens pode promover a formação de leitores competentes, multiculturais e multiletrados. Desta forma, este artigo propõe trazer uma contribuição para que os educadores possam refletir sobre a linguagem literária vinculada à tradição oral e multimodal. Finalmente, são tecidas considerações sobre a relevância da leitura da literatura indígena para conhecer, compreender e valorizar o outro e as diferentes formas de expressão literária.

Palavras-Chave: Literatura Indígena. Literatura Infantil. Leitores. Multiculturalidade. Multiletramentos.

ABSTRACT - The Literature of Indigenous Peoples and the Education of the Multicultural Reader. The aim of this article is to present a discussion on the presence and on the aesthetic/literary characteristics of the texts produced by Native writers. Thus, the focus of this paper lies in pointing out how the reading of Native literature by young readers might lead to the education of competent multicultural and multiliterate readers. In this way, we discuss some aspects that might be taken into consideration when reading Native literature, such as the specific elements of literary language, connected to the oral tradition and to multimodalities. Finally, we discuss the relevance of reading Native literature in order to know, understand and recognize the importance of the other and of different forms of literary expression.

Keywords: Native Literature. Children's Literature. Readers. Multiculturalism. Multiliteracy.

Educação \& Realidade, Porto Alegre, v. 38, n. 4, p. 1175-1189, out./dez. 2013.

1175

Disponível em: <http://www.ufrgs.br/edu_realidade> 
A Literatura dos Povos Indígenas e a Formação do Leitor Multicultural

Escrever sobre a literatura indígena e, em especial, sobre a literatura indígena brasileira para crianças e jovens, significa discorrer sobre um tema ainda novo para muitos educadores. Apesar dos esforços promovidos por órgãos federais e instituições diversas para divulgar as culturas indígenas, estas ainda são uma incógnita para professores e alunos até mesmo nas universidades. Contudo, em face da lei 11.645/2008, que determina que a disciplina de História e Cultura Afro-Brasileira e Indigena seja inserida nos currículos das escolas brasileiras, a lacuna do desconhecimento da literatura indígena precisa ser preenchida.

Todos têm o direito de descobrir, ler e debater os textos produzidos pelos diversos povos indígenas, como forma não só de conhecer visões estéticas e temáticas diferentes, mas também de valorizar o outro, o diferente, que deve ter sua história, sua presença e visão de mundo reconhecidas. Assim, propomos neste artigo discutir a especificidade da literatura indígena para crianças e jovens, a fim de desenvolver uma reflexão sobre como o contato com esta literatura pode promover a formação de leitores competentes, multiculturais e multiletrados.

\section{A Literatura Indígena e sua Leitura}

Cerca de 20 anos após a aprovação da Declaração Universal dos Direitos da Criança (1959), foram redigidos Os Direitos Universais das Crianças a Escutar Contos, pelo Centro Regional para o Fomento do Livro na América Latina e no Caribe (Cerlalc). Segundo este documento, resumido e discutido por Giardinelli (2010, p. 153), "Toda criança/jovem goza a plenitude do direito de conhecer os contos, poemas e lendas de seu país". Com base nesta afirmação, percebemos que conhecer a literatura nacional implica conhecer não só os textos considerados canônicos, mas também textos provenientes da diversidade cultural do país. A literatura de um povo é, na verdade, composta pela literatura de muitos povos. Quando falamos sobre o contato das crianças e jovens com a literatura brasileira, estamos falando de muitas literaturas, culturas e vozes, criadas não só em língua portuguesa, mas também em idiomas nativos, tais como os textos da literatura indígena. Esta literatura, por sua vez, também é composta por textualidades provenientes de muitas culturas e comunidades indígenas. Estes textos merecem ser apresentados ao público não índio e às crianças, como forma de conhecimento e inclusão do outro, como prática de multiletramento (letramento cultural, literário, informacional e crítico) e de leitura de multimodalidades textuais.

O acesso das crianças e jovens aos textos da diversidade cultural de seu país é condição fundamental para assegurar ainda outros direitos constitucionais. Conforme afirma Giardinelli (2010, p. 154):

O direito constitucional de ler se baseia em que a leitura é condição básica para que uma pessoa se eduque e possa continuar, durante toda a sua vida, se for o seu desejo,

1176 Educação \& Realidade, Porto Alegre, v. 38, n. 4, p. 1175-1189, out./dez. 2013. Disponível em: <http://www.ufrgs.br/edu_realidade> 
seu próprio processo de aprendizagem. Baseia-se também em que é a melhor garantia da livre circulação de conhecimento, que é indispensável para a construção de uma cidadania responsável, participativa, reflexiva e com pensamento autônomo. Tudo o que fortalece sua própria identidade e a identidade da nação inteira.

A leitura dos mais variados gêneros textuais e em especial da literatura proporciona, então, o conhecimento da pluralidade cultural do país, o que implica promover também a liberdade e igualdade de expressão, o exercício da cidadania e, consequentemente, o distanciamento de pré-julgamentos baseados em visões estereotipadas e pejorativas do outro e de sua cultura.

Segundo informações disponíveis no site do Programa Povos Indígenas do Brasil, vinculado ao Instituto Socioambiental (ISA), 238 povos indígenas, falantes de mais de 180 línguas diferentes, habitam hoje o Brasil. Este número é significativo, especialmente diante do discurso de desaparecimento dos povos indígenas repassado às crianças nas escolas por décadas. Ainda é possível ouvir professores se referirem aos índios na história brasileira usando verbos no passado, como se os índios não mais contribuíssem para a história e cultura brasileiras.

Vários fatores contribuem para o desconhecimento da literatura indígena brasileira. Embora a produção de obras indígenas no Brasil esteja em crescimento desde a última década do século XX, com autores de várias etnias sendo reconhecidos através de premiações pela qualidade de sua produção literária, a circulação dos textos indígenas brasileiros é ainda reduzida se comparada àquela das publicações de autores indígenas norte-americanos. Mesmo havendo a publicação de contos, poemas, crônicas, textos de diversos gêneros, poucos são os leitores que leem estes textos como obras literárias ou neles buscam mais que o elemento exótico que torna a identidade indígena do autor objeto de curiosidade.

Por sua vez, o espaço escolar promove repertórios canônicos de tradição literária europeia, incluídos em antologias ou considerados leitura obrigatória para referência em qualquer círculo de discussão acadêmica. Professores desconhecem os autores indígenas ou julgam suas obras por critérios canônicos ocidentais de literariedade, o que faz com que não reconheçam nestas textualidades valor estético comparável àquele dos textos recomendados nos currículos e exigidos em exames e concursos. Finalmente, bibliotecários e livreiros têm dificuldade em classificar as obras indígenas, por não compreenderem sua composição multimodal. Há muitos textos indígenas voltados para o público infanto-juvenil, bem como muitos textos distribuídos em prateleiras de literatura infanto-juvenil que são escritos para um público maduro. Apesar das dificuldades apontadas, a literatura produzida pelos índios das mais diversas etnias brasileiras merece visibilidade; sua presença e expressão podem e devem ser contabilizadas e valorizadas.

Educação \& Realidade, Porto Alegre, v. 38, n. 4, p. 1175-1189, out./dez. 2013.1177 Disponível em: <http://www.ufrgs.br/edu_realidade> 
A Literatura dos Povos Indígenas e a Formação do Leitor Multicultural

Vale aqui uma referência ao termo índio, aplicado aos nativos das Américas a partir de um equívoco geográfico e utilizado pelos colonizadores europeus como forma de depreciação do nativo. O termo índio não é removido totalmente do discurso indígena; o nativo dele se apropria e passa a reinventá-lo, possivelmente para construir uma unidade perante olhos ocidentais e para sinalizar o direito à diferença e uma vontade política de resistência à sujeição colonial.

No que tange à literatura nativa brasileira, acreditamos ser necessário um esclarecimento sobre alguns rótulos utilizados, a saber, literatura indianista, indigenista e indígena. O primeiro, indianista, referese mais especificamente à literatura do período romântico brasileiro, voltado para a construção de uma identidade nacional. As obras desta literatura, escritas por autores não índios, colocam o índio como personagem, construído como herói ou vilão, dependendo de seu distanciamento da barbárie que sua cultura nativa representa e da sujeição à cultura do colonizador. As obras indigenistas são produzidas também por não índios e tratam de temas ou reproduzem narrativas indígenas. A perspectiva ocidental característica destas narrativas pode ser evidenciada pela vinculação dos textos nativos a gêneros literários ocidentais, lendas, por exemplo; entretanto, os gêneros textuais e literários são também gêneros culturais, consequentemente construídos a partir de visões de mundo e conceitos diferentes.

Já a produção indígena é realizada pelos próprios índios segundo as modalidades discursivas que lhes são peculiares. As obras indígenas, voltadas para o público infanto-juvenil e para o público maduro, apresentam uma interação de multimodalidades: a leitura da palavra impressa interage com a leitura das ilustrações, com a percepção de desenhos geométricos, de elementos rítmicos e performáticos. Os grafismos indígenas constituem narrativas e devem ser valorizados por sua especificidade, podendo inclusive indicar a autoria do texto indígena, se coletiva/ancestral ou individual. Ademais, a leitura da literatura indígena deve levar em conta o entre-lugar cultural dessa produção que está em uma zona de contato e conflito localizada entre a oralidade e a escrita, entre línguas nativas e europeias, entre tradições literárias europeias e indígenas, entre sujeição e resistência. Textos bilíngues, elaborados em língua nativa e em língua portuguesa, são utilizados como material didático em várias comunidades e escolas indígenas para promover o letramento das crianças nativas e, como resultado, o aprendizado da língua/cosmovisão nativa e da língua portuguesa/cultura brasileira. No entanto, estas obras podem também promover o letramento multicultural e multimodal de crianças e jovens das mais diversas etnias, não ficando este material restrito às comunidades indígenas.

Tendo apontado brevemente alguns traços da literatura indígena, passamos à especificidade da literatura indígena dirigida a crianças e jovens.

1178 Educação \& Realidade, Porto Alegre, v. 38, n. 4, p. 1175-1189, out./dez. 2013. Disponível em: <http://www.ufrgs.br/edu_realidade> 


\section{A Literatura Indígena Infanto-Juvenil}

Tratarmos das características da literatura indígena escrita para o público infanto-juvenil traz, de início, uma dúvida: como traçar a linha que divide literatura para crianças e jovens da literatura para adultos?

Nelly Novaes Coelho (2000, p. 27) afirma que "A literatura infantil é, antes de tudo, literatura; ou melhor, é arte: fenômeno de criatividade que representa o mundo, o homem, a vida, através da palavra”. Segundo estes parâmetros, percebemos que a literatura escrita para o públicoalvo em fase inicial de letramento pode ser tão complexa e elaborada quanto aquela produzida para um público cujas competências leitoras já foram, supostamente, desenvolvidas.

Diante disso, compreendemos a classificação de obras do cânone ocidental, tais como Alice no País das Maravilhas, de Lewis Carroll, e As Viagens de Gulliver, de Jonathan Swift, tendendo ora para o público infanto-juvenil ora para o público acadêmico. Tais obras, e muitas outras, podem ser lidas como romances de aventuras, de autodescoberta, ou como obras de crítica social complexa que podem ser interpretadas em vários níveis. Obviamente, existem adaptações de linguagem para cada público-alvo e cada grupo interpreta o texto conforme suas experiências e repertório. Ainda há a questão de que as editoras optam por direcionar um determinado texto para este ou aquele público. O conceito de literatura infanto-juvenil não deixa, contudo, de exigir reflexão. E, se dentro da literatura canônica ocidental, cujos parâmetros de análise literária são familiares aos educadores, verificamos tal oscilação, como identificarmos, então, as características da literatura para crianças e jovens em uma tradição estético-literária indígena?

Além disso, a noção de quem é criança também é cultural e variável. O que faz parte da experiência de ser criança hoje, em comunidades culturalmente diversas? Como crianças de culturas diferentes leem e interpretam a literatura? Como os educadores fazem a mediação e até que ponto influenciam as leituras literárias de seus alunos? Estas perguntas são válidas e levam à problematização da identidade das crianças e jovens e, consequentemente, de sua literatura.

Para Oliveira (2008, p. 123), atualmente,

[...] a concepção de criança [...] é de um ser em desenvolvimento, [...] em construção de saberes a partir de suas vivências, com direitos a serem respeitados, com necessidades a serem satisfeitas, com liberdade de ser criança e de brincar.

Esta concepção sugere que os textos literários dirigidos às crianças contemplem elementos lúdicos, provoquem o imaginário e a fantasia, ao mesmo tempo em que promovam aprendizagens e questionamentos.

Educação \& Realidade, Porto Alegre, v. 38, n. 4, p. 1175-1189, out./dez. 2013. 1179 Disponível em: <http://www.ufrgs.br/edu_realidade> 
A Literatura dos Povos Indígenas e a Formação do Leitor Multicultural

Segundo Costa (2007, p. 27), pelo contato com a literatura infantil, “[...] a criança estará formando o modo de pensar, os valores ideológicos, os padrões de comportamento de sua sociedade e, em especial, estará alimentando seu imaginário.” Levando em consideração esta perspectiva, verificamos a relevância do contato com literaturas construídas em tradições culturais diversas. Crianças e jovens precisam conhecer e identificar valores, ideologias, padrões de comportamento e também padrões discursivos (de narração) das culturas nas quais estão inseridas, mas necessitam igualmente conhecer os componentes culturais e discursivos de grupos culturais diversificados, até mesmo para que possam compreender melhor sua própria comunidade. A formação de repertório por parte de crianças e jovens e o desenvolvimento de suas competências leitoras, objetivos tão almejados pelos educadores, podem portanto ser promovidos pela leitura de textos indígenas que provoquem curiosidade, sentido de descoberta, desfaçam pré-conceitos e façam pensar.

Acreditamos que crianças e jovens não devem ser subestimados em seu potencial de desenvolvimento de competências leitoras multimodais e multiculturais. Mas para que isto aconteça, os mediadores da leitura precisam privilegiar um enfoque estético das obras literárias. Segundo este enfoque, a literatura deve ser lida como literatura, o que implica a promoção de um olhar sobre a "[...] característica poética da linguagem [...]”, nas palavras de Costa (2007, p. 29), e não a leitura como pretexto para atingir uma finalidade utilitária ou pedagógica.

Vejamos, então, como abordar a linguagem literária dos textos indígenas a fim de promover a sensibilidade estética de crianças e jovens.

\section{Caminhos de Leitura da Literatura Indígena Infanto-Juvenil}

Assim como outras obras literárias, as obras indígenas podem ser lidas com atenção sobre sua linguagem, construída no imbricamento da tradição oral, escrita e performática. Isto significa dizer, por exemplo, que estratégias narrativas da tradição oral aparecem nos textos juntamente com estratégias narrativas de modalidade gráfica e visual.

O processo narrativo de tradição oral é construído com base na repetição, que assegura a continuidade do que é relatado; contudo, repetição não está aqui associada à imutabilidade, mas sim à reinvenção e atualização textual constantes. Walter Ong (1998, p. 47-58) aponta os elementos que caracterizam o pensamento e a expressão fundados na oralidade. Resumimos estes elementos e destacamos: a inserção de estruturas aditivas que conduzem o fluxo narrativo; o uso de fórmulas linguísticas de repetição do já dito, a fim de garantir referência ao que já foi dito e continuidade narrativa; interação com o público de forma a provocar sua reação; referência ao cotidiano da vida humana; construção de uma identificação empática entre narrador, audiência e personagem; vinculação com o presente e uso de conceitos dentro de quadros de referência situacionais.

1180 Educação \& Realidade, Porto Alegre, v. 38, n. 4, p. 1175-1189, out./dez. 2013 Disponível em: <http://www.ufrgs.br/edu_realidade> 
Estas estratégias discursivas estão presentes no universo da contação de histórias compostas na tradição oral para um público heterogêneo, formado por crianças, jovens e adultos. Ao serem traduzidas para o texto escrito, as estratégias discursivas da oralidade podem ainda ser percebidas nos textos indígenas e podem promover a sensibilidade estético-linguística de seus leitores, neste caso, de crianças e jovens. Por exemplo, no texto Vivendo a Tradição, incluído na obra Kurumĩ Guaré no Coração da Amazônia, de Yaguarê Yamã (2007, p. 25), o narrador descreve como as crianças de sua comunidade se reúnem para ouvir histórias:

\begin{abstract}
No que diz respeito à tradição, foi preocupação de meu pai ensinar-me a cultura de nosso povo. Desde criança, assim que comecei a entender as coisas, o que ele mais fazia era arranjar um tempo para contar histórias. Reunia os filhos, sentava-se num banco no meio do terreiro, me chamava para perto, e quando não era eu era o meu irmão caçula. Assim, como se estivesse se preparando para uma apresentação, pegava a flauta e começava a tocá-la bem devagarinho. Aquele som ganhava asas, se propagava pelo ar e chegava melodiosamente ao ouvido das pessoas. As crianças, curiosas, corriam para perto e com o maior respeito o rodeavam sentando-se no chão. Aquele era o ponto de partida para uma viagem ao mundo encantado do povo Maraguá. Quando estávamos todos sentados, meu pai detinha-se por um instante, fitava os olhos em cada olhar presente e começava a história.
\end{abstract}

O fragmento destacado aponta para alguns dos elementos característicos da tradição oral, tais como a presença do contador de histórias, no centro das atenções, a interação com o público, mesmo que apenas pelo olhar, a relação de empatia com a audiência e com o leitor, além de referência ao cotidiano de uma comunidade indígena. Porém, além destes, outros aspectos podem ser notados, como a presença do elemento musical como estratégia de focalização de atenção da audiência no que está por vir, o vínculo emocional construído entre pai e filhos (contador de histórias e audiência) e, consequentemente, o vínculo com a própria tradição de contar histórias, conhecer e dar continuidade à memória ancestral de um povo. Estes aspectos podem ser discutidos, em graus de complexidade diferentes, pelo público de crianças e jovens de culturas indígenas e/ou ocidentais, cada qual segundo suas experiências e visões de mundo, possibilitando conhecimento do outro e desenvolvimento da competência de leitura multicultural.

As obras indígenas estabelecem vínculos entre gerações, especialmente pelas narrativas míticas. Segundo Borges (2003, p. 9), “[...] o mito funciona como um mecanismo aberto de fazer a história, que se sustenta na/pela memória”. Dentre os gêneros narrativos indígenas, o relato mítico assume, em tradições tribais, um papel essencial; o mito, na tradição europeia normalmente vinculado a relatos fantasiosos e

Educação \& Realidade, Porto Alegre, v. 38, n. 4, p. 1175-1189, out./dez. 2013. 1181 Disponível em: <http://www.ufrgs.br/edu_realidade> 
A Literatura dos Povos Indígenas e a Formação do Leitor Multicultural

desvinculado de um discurso histórico ou verdadeiro, assume outras conotações em contextos tribais. Nestes, sugere ligação a narrativas verdadeiras, servindo uma função religiosa. O relato mítico que se refere à origem do mundo, dos deuses e do homem, oferece mais que entretenimento, como poderia ser concebido pela perspectiva ocidental; entendido como verdadeiro saber, o mito fornece as bases que sustentam as relações sociais das comunidades tribais. Portanto, o mito não é construção ficcional, mas construção social.

Desta maneira, as narrativas míticas indígenas anunciam em seus parágrafos de abertura, muitas vezes, a consciência de uma continuidade ou de uma permanência de um saber ancestral; ao mesmo tempo, sinalizam a atemporalidade da história. Isto pode ser percebido pela utilização de fórmulas equivalentes ao "Era uma vez" das histórias canônicas ocidentais. Exemplificamos a presença desta estratégia da oralidade, segundo os parâmetros de construção narrativa indígena, no texto O Sumiço da Noite, de Daniel Munduruku. Nos parágrafos de abertura do texto, lemos:

Há muitos dias a noite não caía no coração da floresta. Homens, mulheres, animais, todos estavam agitados, pois faltava a calma da escuridão para eles poderem dormir. O sol ardia o tempo todo. Ninguém tinha ânimo para fazer nada. Nem mesmo os rituais mais importantes para os moradores da aldeia estavam mais sendo feitos, $\mathrm{e}$ o cansaço tomava conta de todos. Mas quem teria feito a maldade de esconder a noite? E por que alguém teria feito uma coisa dessas? (Munduruku, 2006, p. 5)

O fragmento selecionado leva o ouvinte/leitor para um universo imaginário localizado no início dos tempos, ou seja, apresenta um relato de criação. Ao fazê-lo, desperta a curiosidade da audiência ao propor um enigma, outro componente da narrativa de tradição oral. Ainda, o texto traz perguntas lançadas ao público-alvo que, sendo composto por crianças ou jovens, tem sua atenção voltada para a solução de um mistério. Ao propor este whoddunit indígena, o narrador provoca a imaginação do leitor e a busca por uma explicação culturalmente localizada para a gênese do universo e do homem, por meio do aspecto lúdico.

Além de levar as crianças e jovens ao aprimoramento de competências leitoras da palavra, o contato com a literatura indígena pode capacitar este público a ler outras modalidades discursivas. Utilizamos este termo modalidades para designar recursos semióticos utilizados para a representação (e comunicação) de sentidos construídos social e culturalmente, tais como a imagem impressa ou em movimento, o som, a música, o gesto, a fala. Os estudos desenvolvidos por Kress (2010) propõem que a construção de significados combina vários modos (visual, textual, auditivo, sinestésico, etc.), o que conduz à percepção, por parte dos educadores, da importância de se ensinar a ler e interpretar textos expressos por estas múltiplas linguagens.

1182 Educação \& Realidade, Porto Alegre, v. 38, n. 4, p. 1175-1189, out./dez. 2013. Disponível em: <http://www.ufrgs.br/edu_realidade> 
No que tange aos recursos visuais, as ilustrações estão presentes em grande parte dos textos indígenas, principalmente naqueles dedicados ao público jovem. Há um enredo nos desenhos que lança o leitor para uma rede de significados forjados pela interação de palavra e imagem. Muitas vezes a palavra escrita, tão privilegiada pela literatura canônica, passa a ser um complemento do elemento visual. Assim, a partir da representação visual e gráfica de seu potencial imaginativo, o narrador indígena amplia a latitude e a longitude de seu olhar sobre o mundo e recorre à imaginação como forma de se relacionar com o real, projetando-o ou reformulando-o.

Como os significados das textualidades indígenas emergem de modalidades variadas - escrita, imagens, movimento, áudio - e de suas combinações, a proposta do desenvolvimento de competências relacionadas aos multiletramentos por meio da literatura indígena faz sentido. Sobre os multiletramentos, Rojo (2012, p. 22-23) afirma que:

Em qualquer dos sentidos da palavra 'multiletramentos' no sentido da diversidade cultural de produção e circulação de textos ou no sentido da diversidade de linguagens que os constituem -, os estudos são unânimes em apontar algumas características importantes: (a) eles são interativos; mais que isso, colaborativos; (b) eles fraturam e transgridem as relações de poder estabelecidas, em especial as relações de propriedade (das máquinas, das ferramentas, das ideias, dos textos [verbais ou não]; (c) eles são híbridos, fronteiriços, mestiços (de linguagens, modos, mídias e culturas).

Os multiletramentos apontados por Rojo podem ser desenvolvidos a partir das textualidades indígenas, construídas no imbricamento de tradições, na interação entre contador/narrador e ouvinte/leitora, em composição híbrida (em termos linguísticos, culturais e identitários) e multimodal (pelos recursos utilizados).

Além disso, a literatura indígena pode levar à formação da criança ou do jovem no multiculturalismo que, para Modood (2010, p. 79), “[...] é uma modalidade de integração [...] Trata-se de pessoas que possuem um sentido de identidade grupal, seu próprio senso de vínculo, de pertencimento [...]". A integração das culturas indígenas e não indígenas pode ser estabelecida por meio de inúmeros textos indígenas, tal como na obra Coisas de Índio, de Munduruku (2010). Nela, o autor discorre na apresentação sobre seu propósito ao escrever e publicar seu livro para um público-alvo não índio:

Há muito tempo queria escrever uma obra como esta. Queria escrever, mas não por vaidade, e sim por necessidade de oferecer algum tipo de material para crianças e jovens que queiram conhecer um pouco mais sobre os povos indígenas do Brasil. [...] Por isso aceitei o desafio de escrever esta 'enciclopedinha', que mostra um pouco da riqueza e da sabedoria de algumas culturas indígenas no Brasil (Munduruku, 2010, p. 7).

Educação \& Realidade, Porto Alegre, v. 38, n. 4, p. 1175-1189, out./dez. 2013. 1183 Disponível em: <http://www.ufrgs.br/edu_realidade> 
A Literatura dos Povos Indígenas e a Formação do Leitor Multicultural

Com esta finalidade, Munduruku apresenta ao leitor jovem, não índio, uma visão de sua identidade cultural, coletiva e pessoal, e por meio de textos diversos - míticos, relatos, conversas, mapas, ilustrações - estabelece também um vínculo como contador de histórias e chama o leitor para o conhecimento do outro.

Por sua vez, outro autor indígena, Kaká Werá Jecupé, na obra As fabulosas fábulas de Iauaretê (2007), compartilha com crianças e jovens um texto ilustrado por sua filha, com 11 anos na época da publicação da obra. Ao apresentá-la, Jecupé (2007, p. 7) estabelece alguns dos temas e o tom da obra: "Algumas narrações são divertidas, mas também falam sobre o medo, a coragem, a dúvida, o amor, a morte, a paz, a oportunidade, os erros e os acertos que enfrentamos na vida”. A proposta destes temas indica que a literatura indígena procura ainda levar à percepção de questões vinculadas à existência, questões nem sempre fáceis de serem abordadas, principalmente com crianças. Porém, os temas indicados são fundamentais, pois sensibilizam o leitor, integram-no à realidade $\mathrm{e}$ promovem autoconhecimento e compreensão do si mesmo e do outro.

Em vista dos elementos apontados, a leitura de textos indígenas promove reflexão sobre como o outro vê e lê o mundo e como conta suas histórias. Ademais, a leitura da literatura indígena conduz ainda para a percepção de como formamos identidades e alteridades.

\title{
A Literatura Indígena e a Valorização da Diferença
}

Ao nos referirmos ao outro, ao diferente, é muito comum fazermos isto afirmando que pertence a esta ou aquela etnia. Este vocábulo tem suas raízes etimológicas no termo ethnos, conforme nos mostram Poutignat; Streiff-Fenart em nota referente ao primeiro capítulo do livro Teorias da Etnicidade (1998, p. 23):

\begin{abstract}
Como o assinala Sollors, tal utilização da palavra "étnico" para designar contrastivamente e muitas vezes negativamente povos "outros" é congruente com as raízes etimológicas do termo etnicidade (ethnikos). No mundo grego, o termo ethnos fazia referência aos povos bárbaros ou aos povos gregos não organizados segundo o modelo da Cidade-Estado, ao passo que o termo latino ethnicus designava, na tradição eclesiástica do século XIV, os pagãos em oposição aos cristãos.
\end{abstract}

Podemos ler no uso da palavra etnia pelos gregos e latinos a referência ao outro, ao diferente e, principalmente, àquele que não pertence ao grupo detentor do poder político, econômico e também discursivo. Encontramos implícita na determinação dos grupos étnicos uma relação de dominação na qual, como afirmam Poutignat; Streiff-Fenart (1998, p. 143-144),

[...] a imposição de um rótulo pelo grupo dominante possui um verdadeiro poder formativo: o fato de nomear tem

1184 Educação \& Realidade, Porto Alegre, v. 38, n. 4, p. 1175-1189, out./dez. 2013 Disponível em: <http://www.ufrgs.br/edu_realidade> 
o poder de fazer existir na realidade uma coletividade de indivíduos a despeito do que os indivíduos assim nomeados pensam de sua pertença a uma determinada coletividade.

Desta forma, a identidade étnica pode ser vista como uma ficção, uma construção feita a partir de observações acerca de traços físicos, costumes, origem e localização, fundamentada na diferença.

Com relação aos índios, muitos estereótipos foram construídos pelo colonizador europeu ao longo dos séculos de dominação. As inúmeras comunidades indígenas, apesar de distintas, tiveram sua identidade étnica construída por discursos homogeneizantes que ficcionalizaram os nativos ora como bárbaros, selvagens, primitivos, carentes de lei, fé e rei, ora como bons selvagens, inocentes, desprovidos de ganância. Ademais, as culturas indígenas foram vistas como ágrafas, por não se expressarem utilizando alfabeto reconhecido ou escrita valorizada pelo colonizador. Pelo fato de não compartilharem um mesmo centro de percepção do mundo, os índios foram classificados como bárbaros, especialmente porque os colonizadores consideravam-se portadores de uma civilização, da qual os índios se encontravam despojados.

Contudo, cada encontro com o outro opera uma reavaliação de nossa localização interna e, por vezes, deslocamos nosso olhar para uma percepção de que o outro também nos habita e constrói nossa identidade. Como indica Skliar (2003, p. 58), “[...] depois de Babel estamos exilados de nossa pátria, de nossa língua, de nossa terra, de nosso nome, de nosso mundo. O relato de Babel pode nomear tudo o que é estrangeiro, a condição humana mesma como estrangeiridade". O estrangeiro desestabiliza a ordem, instaura uma espécie de caos e provoca uma relocalização individual ou coletiva. De certa forma, talvez possamos dizer que a condição de estrangeiridade conduz à não estagnação da condição humana.

Com relação à leitura de textos literários e à leitura e compreensão do outro, Abreu (2006, p. 111) declara:

[...] pode ter muito interesse ler e estudar literatura, pois ela pode favorecer o encontro com a Alteridade (alteridade de temas, alteridade de modos de se expressar, alteridade de critérios de avaliação). Não se encontrou, até hoje, nenhum povo que não contasse histórias ou que não cantasse, mas cada povo, ou cada grupo, tem um jeito próprio de fazer isso e uma maneira peculiar de apreciar estas produções.

O contato com a literatura indígena nos desafia e proporciona o encontro com este outro cuja relação com a terra, o divino, a ordem social, a história, as artes, problematiza nossa própria relação com estes elementos e com a nossa própria identidade.

Educação \& Realidade, Porto Alegre, v. 38, n. 4, p. 1175-1189, out./dez. 2013.1185 Disponível em: <http://www.ufrgs.br/edu_realidade> 
A Literatura dos Povos Indígenas e a Formação do Leitor Multicultural

\section{A Literatura Indígena no Espaço da Escola}

De acordo com Jordão (2011, p. 291), "A sala de aula de literatura precisa ser valorizada como lócus potencial para a transformação dos processos interpretativos de alunos e professores, como espaço de confronto com o legitimado". Desta forma, ao promover a escuta/leitura de textos indígenas por crianças e jovens, cabe ao professor proporcionar a oportunidade destes leitores conhecerem e discutirem esta literatura. Pelo contato com as textualidades indígenas, estereótipos podem ser debatidos e desfeitos, visões de mundo restritas têm a chance de ser ampliadas, o multiculturalismo pode alcançar expressão e competências leitoras que envolvem a compreensão de textos multimodais podem ser desenvolvidas.

Para que a literatura indígena alcance a sala de aula, é preciso que seus leitores, professores e alunos, disponham de referenciais teóricos para que as textualidades indígenas sejam interpretadas em sua contextualização cultural e estética. Para tanto, faz-se imprescindível tratar de questões voltadas para a atividade leitora, focando primeiro a leitura do outro para então passar à leitura de suas obras.

Uma reflexão sobre leitura pode ter como ponto de partida as cinco dimensões do processo de leitura propostas por Thérien (apud Jouve, 2002, p. 17-22), assim apresentadas: a leitura como um processo neurofisiológico; um processo cognitivo; um processo afetivo; um processo argumentativo e um processo simbólico.

A leitura como processo neurofisiológico mostra que a atividade leitora é desenvolvida por um conjunto de funções cerebrais e pelo aparelho visual. Com relação à leitura do outro, do índio e de sua produção literária, sua apreensão pode ser determinada por uma programação que faz com que haja uma maneira de ver e interpretar o mundo culturalmente localizada. Em consequência, é importante que os leitores jovens aprendam a perceber como cada cultura conta suas histórias e sua relação com o mundo e com o outro, até mesmo para que as programações culturais possam ser revistas e questionadas, para que visões pré-concebidas e estereotipadas do outro sejam desfeitas.

Como processo cognitivo, a leitura implica a transformação de significantes em significados, solicitando do leitor um "[...] esforço de abstração" (Jouve, 2002, p. 18) e "[...] um saber mínimo que o leitor deve possuir se quiser prosseguir a leitura". (Jouve, 2002, p. 19). Neste caso, a leitura do outro exige o desenvolvimento de competências para que sejam construídos sentidos a partir do que o outro apresenta e para que a leitura do outro ultrapasse o nível do etnocentrismo. Neste caso, crianças e jovens não devem ser menosprezados na sua capacidade de desenvolvimento de competências leitoras, principalmente em face do número de recursos tecnológicos disponíveis para seu multiletramento.

Quanto ao processo afetivo, Jouve (2002, p. 19) afirma que "O charme da leitura provém em grande parte das emoções que ela suscita.

1186 Educação \& Realidade, Porto Alegre, v. 38, n. 4, p. 1175-1189, out./dez. 2013 Disponível em: <http://www.ufrgs.br/edu_realidade> 
Se a recepção do texto recorre às capacidades reflexivas do leitor, influi igualmente - talvez, sobretudo - sobre sua afetividade".

De forma análoga, a leitura do outro faz com que se responda a ele emocionalmente com atitudes de repulsa, rejeição, desprezo, ódio, ou de admiração, respeito, confiança e tentativa de imitação. As emoções dependerão das relações de poder criadas e do prisma de igualdade, inferioridade ou superioridade desenvolvido, determinantes para a apreensão e para o relacionamento com a alteridade. Vale ressaltar a importância desta dimensão e da discussão dos pré-conceitos criados na infância e adolescência para que haja uma sensibilização dos jovens para o respeito e valorização do estilo de vida e de expressão do outro.

O processo argumentativo é apresentado por Jouve (2002, p. 21) como aquele no qual

O texto, como resultado de uma vontade criadora [...] é sempre analisável [...] como 'discurso', engajamento do autor perante o mundo e os seres. [...] Como observa J.M. Adam (1985) em seu estudo sobre a narrativa, 'a narração visa a levar o interpretador em potencial (caso da comunicação escrita) ou atual (caso da comunicação oral) a uma certa conclusão ou desviá-lo dela'.

Como a literatura desafia o leitor pelos caminhos da interpretação, o narrador indígena desafia o leitor pelos caminhos que levam a uma revisão de conhecimentos sobre as culturas nativas, pois o outro age sobre quem o lê.

Com relação ao processo simbólico da leitura, Jouve (2002, p. 22) aponta que

O sentido que se tira da leitura (reagindo em face da história, dos argumentos propostos, do jogo entre os pontos de vista) vai se instalar imediatamente no contexto cultural onde cada leitor evolui. Toda leitura interage com a cultura e os esquemas dominantes de um meio e de uma época.

Embora o outro possa conduzir o leitor pelos caminhos de sua interpretação, a leitura depende do leitor e tem sua fundamentação nos contextos político-econômico e/ou histórico-culturais do leitor, o qual constrói sentidos do outro a partir da sua própria identidade e cosmovisão. Assim, o contato com a literatura indígena pode possibilitar ao leitor não índio uma reflexão sobre sua própria comunidade interpretativa e sua relação com os demais povos.

Portanto, a leitura de diferentes textualidades pode levar à reflexão sobre a complexidade da interação construída com o outro e com sua literatura. Além disso, existem inúmeros outros, e a relação com cada um e com cada voz é diferente, em face de localizações culturais/ ideológicas e de relações de poder. Quaisquer palavras utilizadas para traduzir o outro não são neutras, pois não há neutralidade com relação ao outro, nem um olhar desenraizado.

Educação \& Realidade, Porto Alegre, v. 38, n. 4, p. 1175-1189, out./dez. 2013.1187 Disponível em: <http://www.ufrgs.br/edu_realidade> 
A Literatura dos Povos Indígenas e a Formação do Leitor Multicultural

Quanto à leitura literária, esta é lida na interação texto-leitor, o que significa que o sentido se concretiza em um entrelaçamento cultural, principalmente se o texto parte de uma cultura e tradição literária e chega a um leitor que aprendeu a ler textos literários segundo outra cultura e outra tradição literária.

Para que crianças e jovens se tornem competentes leitores de diferentes textualidades, indígenas, africanas, por exemplo, as dimensões do processo de leitura precisam ser ativadas. Deste modo, o contato com a literatura será desenvolvido a partir do que já se conhece das convenções de leitura para que, então, estes leitores experimentem novas construções discursivas e negociem interpretações decorrentes do diálogo entre o pré-existente e o novo.

\section{Conclusão}

Como tratamos das dimensões do processo da leitura, à guisa de conclusão, refletimos sobre as cinco dimensões (ou tipos) de leitura sugeridas por Perissé (2005, p. 55-64) e que podem ser desenvolvidos em diversas etapas de multiletramentos, a saber: a leitura funcional, recreativa, reflexiva, inspiradora e formativa. A partir do que o referido autor propõe, entendemos a leitura funcional como leitura investigativa, que procura identificar os componentes e a organização do texto; a leitura recreativa diverte, dá prazer; já a leitura reflexiva instiga várias leituras do mesmo texto e faz com que perguntas surjam; a leitura inspiradora motiva o leitor a também escrever, a dialogar com o texto lido pela escritura de novos textos, pela produção de novas maneiras de narrar; finalmente, a leitura formativa transforma o leitor, produz um novo leitor a cada dia, forma o indivíduo/cidadão voltado para o aprendizado constante, para o não acomodamento.

Ao inserirmos a literatura indígena na sala de aula, ao contarmos histórias escritas sob a perspectiva das diversas comunidades indígenas aos nossos alunos e, em especial, às crianças e jovens, possibilitamos que as leituras funcional, recreativa, reflexiva, inspiradora e formativa sejam promovidas. Desta forma, como educadores, motivamos o crescimento de leitores mais competentes, multiculturais e multiletrados, bem como o desenvolvimento de cidadãos que reconhecem a importância das diferenças, valorizam e conhecem a si mesmos e aos outros.

Recebido em 26 de março de 2013 Aprovado em 8 de julho de 2013

\section{Referências}

ABREU, Márcia. Cultura Letrada: literatura e leitura. São Paulo: UNESP, 2006.

BORGES, Luiz Carlos. Os Guarani Mbyá e a Oralidade Discursiva do Mito. In: FERNANDES, Frederico Augusto Garcia (Org.). Oralidade e Literatura: manifestações e abordagens no Brasil. Londrina: Eduel, 2003. P. 1-19.

1188 Educação \& Realidade, Porto Alegre, v. 38, n. 4, p. 1175-1189, out./dez. 2013 Disponível em: <http://www.ufrgs.br/edu_realidade> 
COELHO, Nelly Novaes. Literatura Infantil: teoria, análise, didática. São Paulo: Moderna, 2000.

COSTA, Marta Morais da. Metodologia do Ensino da Literatura Infantil. Curitiba: Ibpex, 2007.

GIARDINELLI, Mempo. Voltar a Ler: propostas para ser uma nação de leitores. Trad. Víctor Barrionuevo. São Paulo: Ed. Nacional, 2010.

JECUPÉ, Kaká Werá. As Fabulosas Fábulas de Iauaretê. São Paulo: Peirópolis, 2007.

JORDÃO, Clarissa Menezes. Da educação literária. In: BONNICI, Thomas; FLORY, Alexandre Villibor; PRADO, Márcio Roberto (Org.). Margens Instáveis: tensões entre teoria, crítica e história da literatura. Maringá: Eduem, 2011. P. 287-295.

JOUVE, Vincent. A Leitura. São Paulo: Editora UNESP, 2002.

KRESS, Gunther. Multimodality: a social semiotic approach to contemporary communication. New York, NY: Routledge, 2010.

MODOOD, Tariq. Multiculturalismo, Etnicidade e Integração: desafios contemporâneos. In: AXT, Gunter; SCHÜLER, Fernando Luís (Org.). Fronteiras do Pensamento. Rio de Janeiro: Civilização Brasileira, 2010. P. 75-92.

MUNDURUKU, Daniel. O Sumiço da Noite. São Paulo: Editora Caramelo, 2006. MUNDURUKU, Daniel. Coisas de Índio: um guia de pesquisa. São Paulo: Callis Ed., 2010.

OLIVEIRA, Maria Alexandre de. A Literatura para Crianças e Jovens no Brasil de Ontem e de Hoje: caminhos de ensino. São Paulo: Paulinas, 2008.

ONG, Walter. Oralidade e Cultura Escrita: a tecnologização da palavra. Trad. de Enid Abreu Dobránszky. Campinas, SP: Papirus, 1998.

PERISSÉ, Gabriel. Elogio da Leitura. Barueri, SP: Manole, 2005.

POUTIGNAT, Philippe ; STREIFF-FENART, Jocelyne. Teorias da Etnicidade: seguido de grupos étnicos e suas fronteiras de Fredrik Barth. Trad. de Elcio Fernandes. São Paulo: Fundação Ed. da UNESP, 1998.

ROJO, Roxane. Pedagogia dos multiletramentos: diversidade cultural e de linguagem na escola. In: ROJO, Roxane; MOURA, Eduardo (Org.) Multiletramentos na Escola. São Paulo: Parábola Editorial, 2012. P. 11-31.

SKLIAR, Carlos. Pedagogia (Improvável) da Diferença: e se o outro não estivesse aí? Trad. de Giane Lessa. Rio de Janeiro: DP\&A, 2003.

YAMÃ, Yaguarê. Kurumi Guaré no Coração da Amazônia. São Paulo: FTD, 2007. Disponível em: <http://pib.socioambiental.org/pt/c/no-brasil-atual/quemsao/povos-indigenas>. Acesso em : 21 out. 2012.

Janice Cristine Thiél é mestra e doutora em Letras pela Universidade Federal do Paraná e professora titular, da área de Letras, da Pontifícia Universidade Católica do Paraná. Desenvolve estudos sobre literatura, leitura e tradução. Seu livro Pele Silenciosa, Pele Sonora: a literatura indígena em destaque (Autêntica, 2012) foi contemplado com o selo Altamente Recomendável FNLIJ 2013 - Produção 2012.

E-mail: janthiel09@gmail.com

Educação \& Realidade, Porto Alegre, v. 38, n. 4, p. 1175-1189, out./dez. 2013. 1189 Disponível em: <http://www.ufrgs.br/edu_realidade> 